\title{
CONSIDERAÇÕES SOBRE O PAPEL DA(O) ANTROPÓLOGA(O) COMO PERITA(O) JUDICIAL EM PROCESSOS DE RECONHECIMENTO OFICIAL DE TERRAS INDÍGENAS A PARTIR DE UM CASO GUARANI ÑANDÉVA
}

\section{Valéria E. N. Barros ${ }^{1}$}

\begin{abstract}
Resumo: O objetivo deste trabalho é refletir sobre os processos de reconhecimento oficial de terra indígenas no Mato Grosso do Sul a partir de uma área reivindicada por uma comunidade guarani ñandéva e que foi identificada como sendo o tekoha Yvy Katu através de processo administrativo devidamente conduzido pela FUNAI e que resultou na publicação da portaria no 1289, de 30 de junho de 2005, que declara ser de posse permanente do grupo guarani em questão a terra indígena Yvy Katu. Processos judiciais movidos pelos proprietários de terras situadas dentro do perímetro demarcado suspenderam o andamento do processo administrativo. No contexto deste litígio, realizei duas perícias antropológicas na região em questão - uma em 2011 e outra em 2013. Nelas, um dos pontos centrais a serem esclarecidos era como e porque os Guarani teriam deixado de viver nas terras atualmente reivindicadas. E isso, por sua vez, conecta-se com outro eixo de discussão proposto por este grupo de trabalho: as violações dos direitos dos Guarani no Mato Grosso do Sul. Assim, partindo dos dados levantados durante minha atuação como perita, pretendo tecer algumas considerações sobre aspectos principalmente metodológicos e éticos que colocam diferentes desafios para os antropólogos envolvidos nas diferentes etapas dos processos de reconhecimento oficial de terras indígenas e na realização de perícias antropológicas no âmbito judicial.
\end{abstract}

Palavras-chave: Antropólogo. Processo de reconhecimento. Terras Guaranis.

\section{INTRODUÇÃO}

O objetivo deste trabalho é refletir sobre a especificidade da pesquisa antropológica realizada no contexto de disputas judiciais em meio aos processos administrativos de reconhecimento oficial de terras indígenas ${ }^{2}$ a partir de minha

1 Doutora em Antropologia Social pela UFSC. Professora do curso de licenciatura em Ciências Sociais da Universidade Federal da Fronteira Sul. Contato: valeria.e.barros@gmail.com

2 Os procedimentos demarcatórios de terras indígenas baseiam-se nas determinações do artigo 231 da Constituição Federal de 1988 e no decreto no 1775 de 1996. São responsabilidade do Poder Executivo Fe- 
atuação como perita antropóloga pela Justiça Federal do Mato Grosso do Sul em processos ligados a uma área reivindicada por um grupo indígena da etnia Guarani Ñandéva ${ }^{3}$ e que foi identificada como sendo seu território tradicional através de processo administrativo devidamente conduzido pela Fundação Nacional do Índio (FUNAI).

No início do século XX, entre 1915 e 1920, o Serviço de Proteção aos Índios (SPI) reservou no espaço que atualmente corresponde ao sul do estado de Mato Grosso do Sul oito lotes para serem destinados aos Guarani Ñandéva e Kaiowá4, com superfície de 3600 hectares cada um. No entanto, a demarcação efetiva destas áreas pela FUNAI deu-se, posteriormente, com extensões inferiores. Esse foi o caso da reserva indígena de Porto Lindo, localizada no município de Japorã, homologada por decreto presidencial em 1991, contemplando uma demarcação realizada pela FUNAI de aproximadamente 1650 hectares.

Assim, a criação dessa reserva, bem como de outras na região em questão, significou apenas que a União procedeu ao reconhecimento da área reservada pelo SPI (ou de parte dela) para os Guarani, sem que fossem realizados os estudos e procedimentos necessários para a caracterização da posse tradicional e, consequentemente, para a delimitação da Terra Indígena (TI) em conformidade com os critérios definidos no artigo 231 da Constituição Federal de 1998. E, dessa forma, a FUNAI, através de procedimento administrativo relacionado à sua própria função de regularizar as terras indígenas, e atendendo ao que determina o decreto no 1775 de 1996, constituiu em 2001 um Grupo Técnico (GT), coordenado pelo antropólogo Fabio Mura, para realizar estudos de revisão de limites de Porto Lindo, que por sua vez resultaram na identificação e delimitação da TI Yvy Katu - ampliando os limites da primeira, que passa a fazer parte dos 9454

deral e conduzidos pelo Ministério da Justiça e pela FUNAI. As etapas do processo administrativo são as seguintes: identificação e delimitação da terra indígena; declaração; demarcação física; homologação; registro; extrusão dos não-índios. Quando há judicialização, o andamento do mesmo fica interrompido.

3 As palavras em Guarani estão grafadas em itálico (por exemplo, o termo "tekoha”), com exceção dos nomes das terras indígenas, e locais de ocupação tradicional (tais como Yvy Katu, Arroyo 'i, Naranjaty, entre outros). Conforme a convenção comumente utilizada em trabalhos antropológicos, termos em Guarani não são flexionados no plural (tal como em "os Guarani" e "diferentes tekoha"). Quando a denominação da etnia aparece como substantivo, é grafada com maiúsculas (Guarani Ñandéva); quando a denominação da etnia aparece com função de adjetivo, é grafada com minúsculas (língua guarani, organização social guarani, etc.) - também seguindo a convenção comumente utilizada por outros pesquisadores.

4 Os Guarani pertencem ao tronco linguístico tupi, e à família linguística tupi-guarani. Apesar de constituírem um núcleo comum, presente em sua cultura como um todo, dividem-se em diferentes parcialidades. A etnologia brasileira aponta para três subgrupos em território nacional (o território tradicionalmente ocupado por eles, antes do estabelecimento das fronteiras dos atuais Estados-Nação, abrangia partes do que atualmente são os territórios do Brasil, Paraguai, Argentina, Uruguai e Bolívia): os Ñandéva, os Kaiowá e os Mbyá (Schaden, 1962). Mas existem muitos debates em torno das parcialidades, e na bibliografia atual podemos encontrar menção a outras denominações, como Avá-Guarani e Chiripá (Mello, 2006 e Albernaz, 2009), entre outras. 
hectares propostos para a delimitação dessa última.

O resumo do relatório circunstanciado produzido pelo GT foi publicado no Diário Oficial da União no dia 02 de março de 2004. Em 30 de junho de 2005 o Ministro da Justiça assinou a portaria $\mathrm{n}^{\circ} 1289$, declarando ser de posse permanente dos Guarani Ñandéva a TI Yvy Katu. Mas o processo administrativo seria em seguida suspenso por conta dos processos judiciais movidos pelos proprietários de alguns dos imóveis rurais situados no perímetro já identificado como TI Yvy Katu contra a FUNAI.

No contexto desse litígio judicial, fui nomeada pelo Juízo da $1^{\text {a }}$ Vara da Justiça Federal de Naviraí, no Mato Grosso do Sul, para atuar como perita antropóloga em dois processos diferentes. Assim, estive na região de Porto Lindo/ Yvy Katu realizando pesquisa antropológica para subsidiar os laudos periciais em duas ocasiões diferentes: em 2011 e em 2013. A pesquisa antropológica nessa situação tem o objetivo de levantar elementos para responder a uma série de quesitos (perguntas) formulados pelo Juízo e/ou pelas diferentes partes envolvidas no processo (que no caso em questão são os proprietários, os Guarani Ñandéva da região de Porto Lindo/Yvy Katu, a FUNAI e o Ministério Público Federal), resultando num laudo pericial antropológico que passará a fazer parte dos autos do processo judicial ${ }^{5}$. Um dos pontos centrais a ser esclarecido é se a área em litígio é ou não território tradicional do grupo que o reivindica.

A Constituição Federal de 1988 reconhece aos povos indígenas os direitos originários sobre as terras que tradicionalmente ocupam. No entanto, diante da enorme diversidade étnica e cultural das populações indígenas no Brasil, a expressão "terras tradicionalmente ocupadas" remete para um amplo leque de possibilidades: cada grupo indígena apropria-se do espaço onde vive a partir de uma lógica específica, ligada aos seus usos, costumes e tradições. Assim, nos relatórios de identificação e delimitação a(o)s antropóloga(o)s precisam demonstrar, através de uma série de procedimentos metodológicos (o uso de dados etnográficos, arqueológicos e históricos, de dados genealógicos, etc.), os vínculos (culturais, sociais e históricos) entre os antigos ocupantes e seus descendentes com determinados lugares para justificar a posse tradicional do grupo em questão. De acordo com o marco jurídico do texto constitucional, a ocupação do mesmo tem que ser efetiva e constante ou há que se comprovar como se deu a expulsão e/ou esbulho. E ainda: áreas que foram objeto de ocupação tradicional no passado,

$5 \mathrm{~A}(\mathrm{o})$ perita(o) é nomeada(o) como um(a) auxiliar do Juízo, e as diferentes partes envolvidas no litígio podem indicar assistentes técnicos, que têm a prerrogativa de acompanhar os trabalhos in loco da perícia e também de produzir pareceres técnicos independentes, que também podem ser anexados aos autos do processo judicial, mediante solicitação da parte interessada ao Juízo. 
mas para as quais não foi possível estabelecer relações entre os antigos ocupantes e descendentes dos mesmos nas gerações atuais que vivem na região em questão são deixadas de fora do perímetro da área identificada, em reconhecimento ao fato de que o procedimento administrativo de regularização fundiária de terras indígenas não permite buscar a recuperação de terras de ocupação imemorial.

No caso da TI Yvy Katu, conforme mencionado acima, a ocupação tradicional já havia sido reconhecida pelo Ministério da Justiça, diante das conclusões do relatório circunstanciado produzido pelo GT designado pela FUNAI. No entanto, isso foi questionado no processo judicial e recolocado como um ponto central nos quesitos que me foram apresentados. Para respondê-los, foi preciso articular conceitos antropológicos e dados etnográficos com determinações administrativas e jurídicas e, partir disso, trazer elementos sobre a especificidade social e cultural dos Guarani e sobre a trajetória vivida por eles junto com outros atores sociais na região em questão.

Assim, partindo de minha experiência na realização desses laudos periciais e dos dados levantados, pretendo tecer algumas considerações sobre aspectos principalmente metodológicos que colocam desafios e mesmo dificuldades na realização de perícias antropológicas no âmbito judicial.

\section{CONTEXTUALIZANDO O LITÍGIO JUDICIAL: $O$ PANORAMA DE ESBULHO E VIOLÊNCIA A PARTIR DO QUAL EMERGE A REIVINDIÇAÇÃOO DA TIYVY KATU PELOS GUARANI ÑANDÉVÁ}

Tanto os dados levantados durante a perícia antropológica por mim realizada, quanto aqueles anteriormente apresentados no relatório circunstanciado de identificação e delimitação da Terra Indígena Yvy Katu (Mura e Thomaz de Almeida, 2002), demonstram que a região em questão era ocupada pelos Guarani Ñandéva em caráter permanente e quase que exclusivo ainda nas primeiras décadas do século XX. Os dados indicam um padrão específico de residência que é típico dos Guarani e amplamente descrito na literatura acadêmica produzida a respeito desse povo. No entanto, uma série de fatores obrigaram os Guarani a abandonar alguns dos espaços hoje reivindicados.

Com o fim da guerra entre o Paraguai e a Tríplice Aliança (1864-1870), inicia-se um novo capítulo na história do contato das populações guarani com as 
frentes de exploração e colonização da sociedade ocidental, que já se desenrolava desde o século XVI, mas que a partir de então levaria a uma drástica transformação do território de ocupação tradicional dos Guarani no espaço ocupado atualmente pelo estado do Mato Grosso do Sul.

O governo brasileiro tratou de delimitar e, na medida do possível, proteger e ocupar, as fronteiras com o Paraguai e outros países sul-americanos.

No caso da região de fronteira entre o Paraguai e o atual Mato Grosso do Sul, a região não estava despovoada: havia um contingente significativo de populações ñandéva e kaiowá ocupando o que eram seus territórios tradicionais. Mas o interesse do Estado brasileiro era ocupar essas regiões com não-índios, de forma que no período pós-guerra, observa-se um avanço das frentes econômicas de ocupação das sociedades nacionais, tanto no Brasil, quanto no Paraguai (MELIÀ, 2004).

Na região compreendida pelo atual Mato Grosso do Sul, o que se viu no pós-guerra foi a concessão de terras do Governo federal para terceiros - e justamente muitas dessas áreas estavam dentro de territórios indígenas.

Em 1872, quando a Comissão de Limites iniciou os trabalhos de demarcação das fronteiras entre o Brasil e o Paraguai, Thomaz Larangeira [sic], fornecedor de mantimentos para a Comissão, natural do Rio Grande do Sul, tomou conhecimento da região e de suas potencialidades quanto à exploração dos ervais ali existentes.

Concluídos os trabalhos da Comissão de Limites, em 1874, Larangeira solicitou ao governo central a concessão para explorar os ervais existentes no antigo sul de Mato Grosso. Em 1882, através do decreto ${ }^{\circ} 8799$, ele obteve do governo imperial o arrendamento das terras para a exploração de erva-mate (ylex paraguayense). Em 1892 fundou a Companhia Matte Larangeira (BRAND, 1997).

Com o advento da República, a área de concessão é sucessivamente ampliada. Em 1895, a área arrendada para a Companhia Matte Larangeira ultrapassava os 5.000.000 de ha, que se estendiam "[...] desde as cabeceiras do ribeirão das Onças, na Serra de Amambay, pelo ribeirão São João e rio Dourados, Brilhante e Santa Maria até a Serra de Amambay e pela crista desta serra até as referidas cabeceiras do ribeirão das Onças" (ARRUDA, 1986: 218). Mas ela não estava interessada nas terras, e sim na exploração dos ervais. Ainda que a área dessa concessão atingisse em cheio os territórios indígenas, de certa forma sua presença retardou a ocupação dessas terras por terceiros durante longo tempo, pois ela não permitia a entrada de colonos nas regiões de sua concessão. Os índios não 
foram expulsos, porque interessavam à Matte Larangeira como mão de obra, mas foram deslocados de alguns dos locais que tradicionalmente ocupavam.

Existem poucas publicações sobre o período em que a Companhia Matte Larangeira atuou em sua área de concessão que remetem para o fato de que a mesma se sobrepunha a territórios indígenas, utilizando essas populações como mão de obra. Tal como afirma Ferreira (2007), a maioria dos historiadores que abordam esse tema e período destacam muito mais o uso de mão de obra paraguaia e, em menor proporção, brasileira, bem como o "pioneirismo" do empreendimento e seu papel como vetor de "desenvolvimento" para a região.

Mas com relação ao trabalho das populações indígenas kaiowá e ñandéva nos ervais, Salsa Corrêa (2002) afirma que a violência estava sempre presente, tanto pela repressão e trabalho compulsório, como pelo estado de miséria e desagregação dos grupos que estavam sujeitos a ele direta ou indiretamente.

Ferreira (2007: 60) também destaca que:

[...] as atividades da Cia. Matte Larangeira provocaram significativas transformações na vida das populações kaiowá e guarani. Em regime de trabalho semi-escravo [sic] e exigindo constantes deslocamentos em busca de novos ervais, as relações alternavam-se entre a troca, por ferramentas e outros utensílios de interesse [dos indígenas], e relações de conflito, confronto e fuga.

A partir de 1916, a Matte Larangeira perde o monopólio de exploração de erva-mate na região, mantendo apenas parte das terras arrendadas. Outros ervateiros passam a atuar na região, tanto brasileiros, quanto paraguaios. Nessa época, o Estado já libera a venda de lotes de terras a terceiros. Após a Revolução de 1930, o governo Vargas encerrou a concessão à Matte Larangeira. Isso foi entre $1943 \mathrm{e}$ 1944. Além disso, transferiu para o governo do estado de Mato Grosso as terras que estavam arrendadas para ela até então. Este, por sua vez, declarou os territórios indígenas não-titulados como terras devolutas e repassou a terceiros - aí sim iniciando um processo acentuado de esbulho contra as comunidades indígenas.

Assim, o processo de ocupação dos territórios guarani no Mato Grosso do Sul por colonos brancos foi gradativo, e as terras só foram efetivamente ocupadas por particulares em fins da década de 1950.

Há que se destacar que, conforme apontado anteriormente, as terras que foram reservadas às populações indígenas no espaço do atual estado de Mato Grosso do Sul entre 1915 e 1928 não atendiam a critérios dessas populações, mas sim a critérios do Estado brasileiro. Áreas arbitrariamente escolhidas foram 
destinadas a eles, pois, em última instância, a ação do Estado visava liberar áreas ocupadas pelos índios para a colonização e exploração econômica.

Em 1927, Pimentel Barboza, funcionário do SPI, percorreu a região sul do Mato Grosso para escolher lugares onde demarcar quatro reservas indígenas para acomodar grupos ñandéva e kaiowá. Foram elas: Caarapó, Ramada, Porto Lindo e Pirajuy - todas em locais de grande concentração de indígenas em função dos trabalhos de colheita e preparo de erva-mate. Um trecho de seu relatório, dirigido ao seu superior, ilustra bem as intenções de liberar espaços para a colonização branca acima mencionadas: "Achando-se esses índios em terras particulares, legalizadas, torna-se imprescindível a obtenção, nas proximidades, de uma área de 3600 hectares, em a qual [sic] possam residir e trabalhar" (BARBOZA, 1927: CXXXVIII).

Nesse mesmo relatório, Pimentel Barboza relata a eleição do local destinado à criação da reserva de Porto Lindo, visto que, segundo ele, na região havia uma significativa população indígena:

[...] por isso escolhi também, na margem direita do Iguatemy, uma área de 3600 hectares, com os seguintes limites: o nascente pelo córrego denominado 'Porto Lindo', pequeno arroio que desemboca perto do porto com esse nome; no norte pelo rio Iguatemy; ao poente pelo córrego Guassori; e no sul com terras devolutas (IBIDEM).

No entanto, os limites indicados por ele não correspondem aos que cercam a área efetivamente delimitada pelo SPI para a reserva indígena de Porto Lindo que, situando-se mais ao sul, não alcança o rio Iguatemi em seu limite norte.

Nessa região escolhida para a criação da reserva de Porto Lindo, a exploração da erva-mate era conduzida por um ex-funcionário da Companhia Matte Larangeira, que já atuava na região antes da criação da reserva, chamado A. Batista. E, justamente, o escoamento da produção de erva-mate era feito através das vias fluviais, de forma que o acesso às margens dos rios (no caso da região em questão, o rio Iguatemi) era extremamente importante na dinâmica dessa atividade e da economia local como um todo (várias mercadorias só chegavam à região pelas vias fluviais, visto que ainda não havia estradas).

Segundo foi levantado por Mura e Thomaz de Almeida (2002), A. Batista participou na definição do local onde a reserva indígena de Porto Lindo seria efetivamente demarcada, através de sua influência junto a políticos locais e mesmo junto a órgãos governamentais como o SPI, pois era de seu interesse a 
manutenção do acesso ao rio Iguatemi e seus portos. Assim, a reserva acabou sendo delimitada a cinco quilômetros do rio Iguatemi, de forma que os grupos familiares que viviam nas cabeceiras e ao longo dos córregos Arroyo 'i, Potrerito e Naranjaty, por exemplo, foram progressivamente afastados de seus locais de ocupação tradicional ${ }^{6}$.

Mas tudo indica que, por trás da expulsão dos Guarani desses locais de ocupação tradicional, estava não só o interesse em explorar e escoar a erva-mate sem empecilhos, mas também a intenção por parte dos ervateiros em, futuramente, regularizar a posse da terra. A. Batista foi uma das primeiras pessoas a requerer a obtenção de títulos definitivos de propriedade na região - não apenas na área do litígio ligada a Porto Lindo/Yvy Katu, mas também na região onde foi identificada a TI Sombrerito (ALMEIDA, 2012).

Assim, no caso dos Guarani Ñandéva que atualmente reivindicam a TI Yvy Katu, a interrupção de sua presença em seu território de ocupação tradicional não se deu por livre e espontânea vontade, mas sim pela pressão para que deixassem o local ou mesmo pela remoção forçada por parte daqueles que se tornaram proprietários das terras. A memória dessa violência está presente nos relatos das pessoas mais idosas do grupo, que vivenciaram essas situações. As pessoas entrevistadas apontam o já referido ervateiro como sendo a principal figura ligada à sua saída da área atualmente reivindicada. No caso de muita(o)s da(o) s entrevistada(o)s, ele teria sido o primeiro branco com o qual ela(e)s tiveram contato dentro do território que tradicionalmente ocupavam ${ }^{7}$. Explorando erva-mate e depois madeira, e posteriormente requerendo e obtendo títulos de propriedade na região, ele teria iniciado um processo onde exerceu diferentes tipos de pressão para que as famílias guarani se retirassem de locais que, até então, elas vinham ocupando continuamente e de forma tradicional.

$\mathrm{Na}$ época em que as primeiras propriedades foram tituladas e que seus proprietários começaram a "abri-las", retirando a vegetação nativa para a formação de pastos ou para a implantação de atividades agrícolas nos moldes ocidentais, os Guarani foram uma mão de obra extremamente útil e sua presença nas propriedades era tolerada.

6 Até as primeiras décadas do século XX, as famílias guarani que viviam na região identificada como sendo a terra indígena Yvy Katu ocupavam em caráter permanente e quase que exclusivo uma extensa área cuja abrangência liga-se a rios e córregos que são afluentes do rio Iguatemi (como Jakarey, Guassori, Arroyo'i, Potrerito, Naranjaty, Limaty, Yvu, Kaxi Kue, Remanso Guasu, entre outros), distribuindo-se em suas cabeceiras e ao longo de seus cursos.

7 O que é significativo enquanto demonstração do esforço que essas famílias guarani faziam para manterem-se afastadas dos não-indígenas que já circulavam na região por essa época (o contingente de pessoas envolvidas na Guerra do Paraguai, as expedições de reconhecimento e demarcação das fronteiras realizadas na época, etc.) 
Na década de 1970, quando ainda havia muitos pequenos proprietários na região, em sua maioria cultivando algodão e café, os Guarani igualmente puderam se engajar como mão de obra nas atividades agrícolas ligadas ao cultivo desses produtos e, novamente, podendo circular ou mesmo morar dentro de seus antigos territórios. Mas à medida que estas pequenas propriedades foram dando lugar às fazendas e à pecuária, os Guarani não conseguiram mais empregos e viram seu acesso aos antigos territórios ficar cada vez mais restrito.

Já na década de 1990, os índios passariam a sofrer pesadas restrições a seus deslocamentos, segundo eles, porque os proprietários tinham medo de sua presença em seus territórios tradicionais ocupados pelas fazendas.

Ou seja, temos um longo processo no qual, mais ou menos a partir das décadas de 1920/1930, os Guarani Ñandéva tiveram que deixar seus locais de ocupação tradicional por conta dos diferentes fatores e eventos acima apontados. No entanto, é importante ressaltar que nem todas as famílias deixaram os locais de ocupação tradicional nessa época e que a saída dos Guarani do perímetro maior de Yvy Katu foi um processo longo e complicado e, para entendê-lo, algumas considerações são necessárias.

A atitude dos Guarani de não se oporem (pelo menos não de forma violente e combativa, travando embates diretos com os não-índios) a figuras como A. Batista (e outros não-índios que depois também atuaram no sentido retirar famílias guarani de suas propriedades, ou de impedir a circulação delas no interior das mesmas) está ligada a estratégias de resistência que foram colocadas em prática por eles desde o período colonial (e que em certo sentido são usadas ainda hoje) e que se relacionam diretamente com uma característica própria do ethos guarani: uma atitude que evita enfrentamentos diretos, baseada num modo de ser não-agressivo, que está ligado a uma ética que perpassa o xamanismo e norteia o comportamento das pessoas ao longo de sua vida, nas diferentes situações vivenciadas por elas. Assim, ao contrário dos grupos de origem Jê, como os Kaingang e Xocleng, por exemplo, que na região sul e sudeste do país ofereceram forte resistência à entrada das frentes colonizadoras em seus territórios, travando com elas embates bélicos que resultariam em pesadas baixas para ambos os lados (conforme apontam, por exemplo, os trabalhos de Santos, 1987, Tommasino, 1995 e Mota, 1998), a estratégia dos Guarani, desde o início do contato, foi a de evitar embates diretos e tentar preservar ao máximo sua autonomia (ainda que isso significasse ter que se afastar, mesmo que temporariamente, de certos locais de ocupação tradicional). 
Um outro ponto que gostaria de considerar aqui é a questão da língua. Algumas das pessoas entrevistadas por mim durante os trabalhos in loco da perícia afirmaram que na época em que foram retirados de seus locais de residência, os índios falavam apenas a língua guarani (algumas delas não falam fluentemente $o$ português até hoje). Mas alguns ervateiros e pessoas que trabalhavam para eles falavam o guarani paraguaio- pelo fato de serem paraguaios ou porque circularam amplamente naquela região de fronteira ao longo de sua trajetória de vida. E, quando começaram a trabalhar nas atividades ligadas à erva-mate, ou nas fazendas da região, os Guarani foram aprendendo o português. No entanto, do ponto de vista antropológico, há que se destacar que, por mais que houvesse uma comunicação entre os diferentes sujeitos envolvidos na situação da qual estamos tratando, com certeza ela era muito problemática. Isso porque, tal como coloca Cardoso de Oliveira (1998), para além da barreira linguística, havia uma barreira cultural, e com certeza cada um dos lados envolvidos no processo expressava categorias simbólicas bastante distintas em seus discursos - fossem eles proferidos em guarani ou português. No caso dos Guarani, não havia concepções de exclusividade territorial no interior de sua cultura, bem como não fazia sentido a ideia de terra como mercadoria da qual era possível dispor. É possível então dizer que, nessa época, os Guarani não estavam totalmente cientes das implicações contidas no fato de que aquelas terras, tradicionalmente ocupadas por eles até então, passaram a ser propriedade privada. Essa consciência, no entanto, seria construída ao longo do tempo, resultando no movimento de retomada das terras tradicionais que eclode na década de 2000, mas que estava em andamento muito tempo antes disso.

Assim, trabalhos como os de Thomaz de Almeida (2001) reportam que, mesmo depois da criação de áreas reservadas para os índios no Mato Grosso do Sul, famílias ou grupos de famílias continuaram ocupando terras convertidas em propriedades particulares, insistindo em permanecer nelas por considerarem-nas seu lugar. Mantinham-se nos trechos que ainda contavam com mata, ou que eram pouco explorados pelos novos proprietários, circulando pelos interstícios da nova configuração espacial estabelecida na região. Outra estratégia adotada pelos Guarani para permanecerem em seus territórios tradicionais e que estavam sendo requeridos e titulados por não-índios foi a de vender sua força de trabalho nas propriedades ali instaladas. A maioria das propriedades particulares da região do litígio foi formada com força de trabalho guarani, numa situação paradoxal onde os índios desbravaram seu próprio território para os brancos (LANDA, 2005; COLMAN, 2007 e BRAND, 1997). 
Monteiro (1981) menciona um relatório de um funcionário do SPI datado de 1948, onde consta que no então distrito de Iguatemi (onde se localizava Porto Lindo), numerosas famílias indígenas estavam vivendo fora das áreas reservadas, muitas delas em propriedades particulares ou em terras tidas como devolutas e que estavam sendo rapidamente ocupadas, sendo então os índios expulsos desses lugares. Neste documento, consta um dado importante: a população indígena aproximada da reserva de Porto Lindo era de 250 pessoas; no distrito de Iguatemi, a população indígena aproximada era de 1500 pessoas. Esse grande contingente de índios seria aos poucos obrigado a se dirigir para as reservas, e o próprio SPI teria encaminhado muitas famílias para a área de Porto Lindo e também para a reserva Ramada (também chamada de Sassoró).

No trabalho de Couto (2007), encontramos uma entrevista com o reverendo Rubens Carneiro, um dos responsáveis pela implantação da Missão Evangélica Presbiteriana na reserva de Porto Lindo. Nessa entrevista, ele afirma que quando chegou na região de Iguatemi, em 1960, havia em Porto Lindo apenas 80 índios, ao passo que quando ele deixou a região, transferindo-se para Dourados, em 1976, a população subira para cerca de 1500 pessoas. Essa afirmação não bate exatamente com os censos realizados na época pelo órgão indigenista, mas o importante a reter dela é que, de fato, ao longo dessa década a população aumentou muito.

Os dados demográficos disponíveis sobre Porto Lindo e apresentados por Mura e Thomaz de Almeida (2002:71), indicam que num período de 24 anos (entre 1947 e 1971), a população vivendo no interior da reserva teria se mantido mais ou menos constante (variando entre aproximadamente 250 e 310 pessoas). No entanto, em três anos esse número praticamente dobraria - a população em 1974 chegando a aproximadamente 570 pessoas. No início dos anos 1980 a população girava em torno de 1100 pessoas.

Os números, então, apontam mudanças repentinas no número de habitantes de Porto Lindo, indicando claramente a movimentação de grandes contingentes de famílias indígenas para dentro da área reservada. E não apenas as famílias que viviam no perímetro do tekoha Yvy Katu foram para lá. Segundo Mura e Thomaz de Almeida (ibidem), famílias que estavam sendo expulsas de seus territórios tradicionais em regiões próximas (tais como Sombrerito, Laguna Piru, Vito'i Kue, Mbokajá, Garcete Kue, Cerrito e Jaguapiré) também se dirigiram para lá.

Inicialmente então houve um "inchaço" populacional em Porto Lindo por conta dos vários grupos para lá deslocados ou que para lá se dirigiram (esponta- 
neamente, porque eram aliados dos grupos do tekoha Yvy Katu; ou forçadamente, porque para lá foram conduzidos pelo órgão indigenista ou outros grupos e atores sociais $\left.{ }^{8}\right)$. Apenas posteriormente seria possível observar um crescimento vegetativo significativo da população, constatado nas últimas gerações.

Essa situação vivida pelos Guarani Nandéva de Porto Lindo/Yvy Katu não foi algo isolado. Com a entrada cada vez mais intensa de frentes de colonização nessa região do então estado do Mato Grosso a partir do século XX, inúmeras comunidades foram desalojadas de seus antigos tekoha e obrigadas a se instalar nas reservas oficiais. Brand (1997), em sua tese de doutorado, apresenta uma extensa relação de aldeias tradicionais guarani e kaiowá destruídas ao longo do século XX em Mato Grosso do Sul, bem como um mapa com suas localizações.

Além disso, a entrada dos contingentes populacionais ligados às frentes colonizadoras traria um outro problema para os Guarani: as epidemias. De acordo com Brand (1997) e Pereira (2004), nas primeiras décadas do século XX os Guarani foram intensamente atingidos por elas nessa região.

É importante também destacar que nem todas as famílias que deixaram o perímetro maior do tekoha Yvy Katu foram viver na área reservada de Porto Lindo. Algumas famílias foram para locais onde viviam seus parentes no Paraguai (como Bajada Guassu e Guavira Poty), ou ainda para outras áreas indígenas demarcadas no próprio estado de Mato Grosso do Sul (como Amambai, Sassoró, Cerrito e Dourados) ou no Paraná (principalmente juntando-se a grupos que vivem na região de Guaíra). Algumas pessoas, ainda, passaram a viver em fazendas ou nas cidades da região, e mesmo em áreas que estão sendo atualmente reivindicadas pelos Guarani, mas que ainda não foram regularizadas.

Assim, mesmo sendo forçados a se retirar de seus locais de ocupação tradicional para a área reservada de Porto Lindo, os Guarani continuaram ocupando esses locais através de diferentes formas ${ }^{9}$ (caçando, coletando, pescando, vendendo sua força de trabalho nas propriedades que ali se instalaram, etc.). E, justamente quando não foi mais possível se manter neles, ainda que através de interstícios, o movimento para sua retomada tem início.

8 Muitos dos relatos administrativos do órgão indigenista analisados por Brand $(1993,1997)$ indicam a existência dessa prática de translado de índios, que eram removidos de seus territórios tradicionais e levados para as reservas. Isso era feito não só pelo órgão indigenista, como também por missionários e proprietários particulares. Assim, algumas das famílias guarani que atualmente reivindicam a TI Sombrerito, por exemplo, moraram durante muito tempo em Porto Lindo, apenas recentemente conseguindo retomar (ainda de forma parcial) seu território tradicional.

9 Cabe aqui destacar que Porto Lindo fazia parte do que eles consideravam ser o tekoha Yvy Katu, mas era apenas uma pequena parte dele, já ocupada por determinadas famílias, às quais os grupos expulsos de seus próprios locais de assentamento foram obrigados a se sobrepor. 
Tal como coloca Brand (1997), à medida que ocorre uma radicalização do confinamento ao longo do século XX, também inicia-se um movimento de quebra desse processo histórico por parte dos índios. Conforme foi possível levantar a partir das entrevistas realizadas com os Guarani de Porto Lindo/Yvy Katu, a falta de espaço e de acesso aos antigos locais de caça, pesca e coleta, foi um dos fatores principais para o início do movimento de retomada das terras tradicionais, que começou a ser articulado pelo grupo ainda no final dos anos 1970.

Assim, é possível dizer que ao longo do contato com a sociedade ocidental, os Guarani foram criando estratégias e formas de atuação política no novo contexto em que se viram inseridos - seja em relação às políticas indigenistas, seja em relação aos segmentos sociais que ocuparam suas terras transformando-as em fazendas agrícolas e/ou pastoris e mesmo cidades. Esse processo resultou no movimento de retomada de seus territórios tradicionais no presente.

A primeira reivindicação oficial da comunidade guarani ñandéva de Porto Lindo no sentido de recuperar o que eles consideram seu território tradicional é uma carta com a data de 24 de abril de 2001 dirigida à FUNAI. Trata-se de um documento/carta manuscrita, assinada pelas lideranças e membros da comunidade e encaminhada ao órgão indigenista.

Conforme foi possível levantar a partir das entrevistas realizadas durante os trabalhos in loco da perícia e mesmo das informações contidas no laudo de Mura e Thomaz de Almeida (2002), a mobilização dos Guarani Ñandéva de Porto Lindo em torno da reivindicação expressa nesse documento manuscrito enviado à FUNAI teve como uma de suas motivações o fato de que, na época, eles foram surpreendidos por um processo paralelo de reivindicação fundiária. Uma das fazendas que fazem parte do território que eles reconhecem como sendo seu antigo tekoha, foi declarada improdutiva pelo Instituto Nacional de Colonização e Reforma Agrária (INCRA) e passou a ser pleiteada pelo Movimento dos Trabalhadores Rurais Sem-Terra. Ou seja: o grupo já estava se articulando em torno do movimento de reivindicação e esse fato se somou a um conjunto maior de motivações, levando a uma postura mais incisiva dos Guarani no tocante à reivindicação da regularização da terra que já então afirmavam ser sua, requerendo, através do documento que encaminharam à FUNAI, que as medidas necessárias para isso fossem tomadas. Em resposta a essa reivindicação, a FUNAI constituiu em 2001 o grupo técnico coordenado pelo antropólogo Fabio Mura para realizar as devidas pesquisas na região. O relatório de identificação e delimitação da terra indígena Yvy Katu havia sido concluído e entregue à FUNAI em 2002, sem que, no entanto, o processo administrativo tivesse algum prosseguimento. Assim, no 
final de 2003, os Guarani Ñandéva resolveram ocupar as propriedades particulares situadas dentro do perímetro da área por eles reivindicada.

O que se seguiu a esse movimento de ocupação das propriedades localizadas dentro do perímetro da área reivindicada pelo grupo como sendo o tekoha Yvy Katu - e que, do ponto de vista dos Guarani, era uma retomada de seus territórios - foi que no dia 14 de janeiro de 2004 a Justiça Federal de Dourados concedeu aos proprietários a reintegração da posse, determinando que a FUNAI retirasse as famílias indígenas do local. No entanto, em 21 de fevereiro de 2004, outra decisão da Justiça Federal suspendeu a reintegração de posse, determinando a permanência dos Guarani no local até a finalização dos processos judiciais.

Assim, por expressa autorização da Justiça Federal, foi fixada em 2004 uma área de $10 \%$ de cada uma das três propriedades maiores dentro desse perímetro para a permanência provisória dos Guarani Ñandéva, enquanto o processo de demarcação da TI Yvy Katu segue os trâmites legais. Desde então várias famílias estão instaladas nesses locais, ali construindo suas casas e roças.

Dessa forma, os Guarani Nandéva conseguiram pressionar a FUNAI, no sentido de fazer com que o órgão indigenista desse continuidade ao processo envolvendo a demarcação da área já identificada e delimitada e, em 30 de junho de 2005, o Ministro da Justiça assinou a portaria $\mathrm{n}^{\circ} 1289$, declarando de posse permanente do grupo a TI Yvy Katu. No entanto, o processo administrativo seria novamente suspenso em função dos processos movidos na esfera judicial por diferentes proprietários. E é neste contexto de luta e disputas que se insere minha atuação como perita.

\section{O TRABALHO ANTROPOLÓGICO NO CONTEXTO DAS PERÍCIAS JUDICIAIS: DIFICULDADES E DESAFIOS}

A pesquisa antropológica apoia-se no método etnográfico que, por sua vez, está associado a uma prática de trabalho de campo baseada na observação direta e em uma convivência mais ou menos prolongada do(a) pesquisador(a) junto ao grupo social a ser estudado - os dados sendo produzidos a partir da inter-relação e interação entre o(a) pesquisador(a) e os sujeitos pesquisados, através de procedimentos metodológicos eminentemente (mas não exclusivamente) qualitativos. Valendo-se de diferentes instrumentos de pesquisa (observação direta, conversas formais e informais, entrevistas, levantamento genealógico, demográfico, etc.) e através de sua participação efetiva nas formas de sociabilidade por meio das quais a realidade investigada se apresenta, o(a) pesquisador(a) consegue pro- 
duzir uma "descrição densa" (GEERTZ, 1989) das formas sociais e culturais do grupo estudado. Mas isso leva tempo - tanto "lá" (em campo), quanto "aqui" (no gabinete) (GEERTZ, 2005).

No contexto de uma perícia judicial, a pesquisa antropológica é realizada através de um tipo de interação que foge dos padrões "clássicos" dessa área do conhecimento (por exemplo porque tem como pano de fundo uma situação de disputa judicial onde os sujeitos pesquisados estão entre as partes envolvidas; pelo fato de que a(o) antropóloga(o) tem que ser acompanhada(o) em todas as etapas pela(o)s assistentes técnica(o)s das partes e suas respectivas equipes de apoio; porque se realiza num curto espaço de tempo, entre outros aspectos).

Por conta disso, é essencial que a(o) perita(o) antropóloga(o) tenha qualificação reconhecida e conhecimento prévio do grupo étnico ${ }^{10}$ envolvido no litígio e de suas especificidades culturais e sociais. No caso de minha experiência como perita, a busca de dados e a análise dos mesmos esteve orientada por questões conceituais e etnográficas aprendidas e acumuladas por mim ao longo de minha formação acadêmica e das pesquisas desenvolvidas anteriormente junto aos Guarani Ñandéva (BARROS, 2003 e 2011). Sem isso não seria possível penetrar nas complexas camadas que compõem a trajetória do grupo guarani envolvido no litígio judicial em questão em tão curto espaço de tempo e reconhecer as singularidades de seus "usos, costumes e tradições", colocados em prática por eles nesse contexto vivido.

Os procedimentos metodológicos ${ }^{11}$ adotados por mim para chegar ao resultado final apresentado no laudo pericial antropológico foram os seguintes: a) leitura e análise dos dados e documentos contidos nos autos dos processos judiciais; b) revisão bibliográfica sobre a legislação indigenista brasileira; c) levantamento, revisão e análise de ampla bibliografia ligada à região e ao grupo indígena em questão, produzida a partir de diferentes campos do conhecimento, como a própria antropologia, mas também a arqueologia e a história; d) pesquisas in loco na região do litígio; e) transcrição das entrevistas; f) organização e análise dos dados bibliográficos e etnográficos; g) redação do laudo pericial antropológico.

Gostaria de me deter sobre as pesquisas in loco pois, remetendo novamente ao "estar lá" e "estar aqui", de Geertz (2005), se todas as outras etapas se realizaram em meu escritório, essa envolveu meu deslocamento até o local do litígio

10 A "qualificação reconhecida" é uma exigência do decreto nº 1775 de 1996 para a nomeação da(o) antropóloga(o) que realiza um estudo de identificação e delimitação de terra indígena e tem sido seguida também na nomeação da(o)s perita(o)s pelo Juízo em processos judiciais.

11 Sobre os procedimentos metodológicos adotados por outra(o)s antropóloga(o)s em perícias judiciais ver, por exemplo, os trabalhos de Oliveira e Pereira (2009 e 2012). 
- demandando, para além do domínio sobre questões teóricas e metodológicas, uma série de cuidados éticos para garantir o andamento dos trabalhos e um ambiente de respeito a todas as pessoas envolvidas.

Uso o termo "pesquisa in loco" e não "trabalho de campo" porque na perícia o contato direto com o grupo se deu em circunstâncias bastante formais e pontuais e os dados foram obtidos apenas através de entrevistas (e não de procedimentos e vivências variadas como ocorre em outros contextos de pesquisa antropológica).

A data de início e término dos trabalhos in loco precisa ser comunicada ao Juízo com antecedência pela(o) perita(o) nomeada(o), para que as partes envolvidas no processo judicial possam tomar ciência do cronograma e acompanhar as atividades, caso queiram fazer isso. Nesse caso, seus assistentes técnicos, indicada(o)s anteriormente ao Juízo, têm a prerrogativa para isso.

Nas duas perícias realizadas por mim o cronograma dos trabalhos in loco (cerca de uma semana), iniciou-se com uma reunião no prédio da Justiça Federal de Naviraí (MS), na qual estiveram presentes a(o)s assistentes técnica(o)s indicada(o)s pelos autores dos processos, pela FUNAI e pelo Ministério Público Federal. Em 2013 estiveram presentes também os autores dos processos (e/ou seus representantes legais) e seu advogado. Nessas reuniões, expus a metodologia que seria utilizada nos trabalhos in loco: basicamente, a utilização de um questionário semiestruturado, com questões elaboradas a partir de vários pontos colocados nos quesitos apresentados pelas partes envolvidas nos processos judiciais, que deixava em aberto a possibilidade de utilização de outros instrumentos qualitativos (como a utilização da história de vida dos sujeitos e de dados genealógicos), a depender do andamento das entrevistas e da disposição da(o)s entrevistada(o)s para falar de certos temas em detrimento de outros.

Nos dias que se seguiram às reuniões que iniciaram o cronograma dos trabalhos in loco, foram realizadas entrevistas com indígenas e não-indígenas na área do litígio, nos municípios de Japorã (onde se localizam Porto Lindo e Yvy Katu) e Iguatemi (ambos no MS). Neste último local também foram levantados dados sobre os Guarani que vivem na área do litígio junto ao polo local da Secretaria Especial de Saúde Indígena (SESAI). Esses trabalhos foram acompanhados por grupos significativos de pessoas, formados pela perita e seu assistente, a(o) $\mathrm{s}$ assistentes técnica(o)s das diferentes partes e suas respectivas equipes, e as lideranças indicadas pela comunidade indígena. Dessa forma, cada entrevista foi acompanhada por todas essas pessoas, ainda que só a perita e a(o)s assistentes 
técnica(o)s designados pelas partes nos autos dos processos pudessem fazer perguntas para as pessoas entrevistadas.

As entrevistas com os Guarani foram realizadas em Porto Lindo, em 2011 num espaço da escola e em 2013 em uma edificação próxima a ela utilizada pela equipe da SESAI. Nas duas ocasiões a presença da perita e do grupo acima mencionado foi negociada com as lideranças da comunidade, que nos permitiram usar esses espaços. A opção por trabalhar dessa forma, centralizando a realização das entrevistas em um único local, deveu-se ao fato de que o deslocamento desse grupo de pessoas dentro da área de Porto Lindo/Yvy Katu tomaria muito tempo e poderia trazer transtornos e constrangimentos para os Guarani. Dessa forma, a equipe da FUNAI, por já conhecer a região da terra indígena, ajudou no translado de algumas pessoas mais velhas e com dificuldades de locomoção até o local onde estavam ocorrendo os trabalhos da perícia.

Durante as entrevistas, foi adotado o seguinte procedimento: eu iniciava explicando a cada um(a) do(a)s entrevistado(a)s que se tratava de uma perícia judicial, que haveria uma dinâmica a ser seguida e que a conversa estava sendo registrada em áudio e vídeo. Se a pessoa consentia em participar, eu iniciava a entrevista. Após fazer minhas perguntas, passava a palavra para cada um dos assistentes técnicos das partes envolvidas no processo (sempre na mesma ordem), para que pudessem colocar os seus questionamentos livremente. Registrei apenas o áudio das entrevistas, mas a(o)s assistentes técnica(o)s dos autores dos processos registraram-nas também em vídeo. Solicitei sempre a ela(e)s que posicionassem as câmeras de forma a não atrapalhar o andamento das entrevistas, nem de forma invasiva, para evitar que as pessoas se sentissem constrangidas num contexto que já estava cercado por várias formalidades que não são comuns na pesquisa antropológica. No caso das entrevistas realizadas com os Guarani, nos diferentes dias de trabalho, um representante da comunidade indígena (um homem guarani) esteve sempre presente, atuando também como tradutor no caso das entrevistas feitas com pessoas que tinham pouca familiaridade com o português (a tradução era feita simultaneamente). Tanto as partes autoras dos processos quanto a comunidade indígena indicaram pessoas a serem entrevistadas durante os trabalhos in loco da perícia. Como perita, também solicitei diretamente a entrevista de algumas pessoas diante de um mapeamento prévio de pontos contidos nos quesitos e que precisavam ser esclarecidos.

A adoção dessa dinâmica rígida no contexto da realização das entrevistas teve a intenção de reforçar a questão da imparcialidade (frequentemente cobrada 
de mim na condução dos trabalhos ${ }^{12}$ ) e para que a(o)s assistentes técnica(os) das partes envolvidas no litígio não se sentissem prejudicada(o)s de alguma forma. Toda(o)s puderam colocar livremente suas questões para as pessoas entrevistadas e isso contribuiu para evitar tensionamentos maiores num contexto já marcado por uma situação de litígio na qual acusações mútuas entre as partes vieram à tona - dado o conflito instalado na região entre os proprietários dos imóveis rurais localizados dentro do perímetro da TI e os indígenas que a reivindicam. A(o)s entrevistada(o)s também puderam falar livremente nos casos em que quiseram acrescentar narrativas para além das perguntas a ela(e)s dirigidas.

Mas mesmo nesse contexto, é importante ressaltar que as entrevistas realizadas não podem ser confundidas com "tomadas de depoimento" ou com um interrogatório. Em alguns momentos, várias pessoas estavam participando juntas das entrevistas (por exemplo: casais, ou pais e filhos, ou irmãos, ou vizinhos). Cada uma era entrevistada individualmente por mim e pela(o)s assistentes técnica(os), que só podiam se manifestar na ordem estipulada e combinada previamente, mas a(o)s entrevistada(o)s podiam interagir livremente entre si. Minha intenção como antropóloga (e perita nomeada) foi manter uma interlocução com as pessoas entrevistadas, sem se incomodar com intervenções umas das outras nas respostas dadas, visto que nas pesquisas antropológicas não existe uma preocupação de "contaminação" ou influência sobre os discursos proferidos pelos sujeitos pesquisados. As intervenções e complementos, nas ocasiões em que várias pessoas estavam juntas no ambiente em que ocorreram as entrevistas, são parte constitutiva do contexto social de interação entre os sujeitos e fontes mesmas de dados.

É importante destacar que para poder esclarecer se houve ou não ocupação tradicional na área do litígio, se fazia necessário reconstruir as relações que se estabeleciam entre as famílias indígenas e o local que está sendo reivindicado por elas atualmente. E, nesse sentido, foi fundamental trabalhar com as narrativas do próprio grupo acerca dos acontecimentos vivenciados por eles ou por seus antepassados. Essas narrativas, articuladas no diálogo estabelecido durante as entrevistas, foram importantes para que se pudesse acessar a memória histórica do grupo sobre os acontecimentos que teriam resultado na sua saída dos locais

12 A perícia realiza-se num contexto de tensão e conflitos onde determinados atos da(o) perita(o) podem ser interpretados pelas partes envolvidas como refletindo certos posicionamentos parciais em benefício de um ou outro grupo. Constantemente tive que dialogar com a suspeita, bastante cristalizada no senso comum da sociedade brasileira, de que a(o)s antropóloga(os) são sempre "a favor dos índios", e que os laudos produzidos por ela(e)s, portanto, nunca são imparciais. Muitas pessoas desconhecem o fato de que, no campo científico, a imparcialidade não exclui uma atitude de respeito e empatia para com as pessoas envolvidas no contexto de uma pesquisa. 
atualmente reivindicados, bem como para acessar o tipo de lógica cultural que permeia a relação que eles estabelecem com o referido espaço, que afirmam ser seu tekoha.

Os dados levantados nas entrevistas, por sua vez, foram submetidos a uma série de procedimentos metodológicos, justamente para combater a possibilidade de serem levados em conta apenas fatos parciais. As generalizações e conclusões apresentadas no laudo pericial foram balizadas pelo confronto das entrevistas entre si, e delas com os dados presentes na bibliografia consultada, bem como com os conceitos próprios do campo antropológico.

Dessa forma, as técnicas utilizadas na coleta e interpretação dos dados, na manipulação das fontes de informação e a forma como foi utilizado o referencial teórico seguiram padrões estipulados e aceitos academicamente, ainda que numa situação colocada em outro contexto e diante de exigências específicas.

A respeito dessas especificidades colocadas pelo campo jurídico, gostaria também de destacar que mesmo tendo clareza do fato de que uma perícia judicial exige da(o) antropóloga(o) um diálogo interdisciplinar com outras áreas do conhecimento - como o Direito - , procurei em minha atuação como perita não extravasar os limites de minha especialidade e formação acadêmica (quesitos de cunho exclusivamente jurídico não foram respondidos por mim).

Mesmo adotando um formato mais rígido na condução das entrevistas, não foi possível evitar de todo os tensionamentos inerentes à situação. Em muitas ocasiões, as pessoas confundiam a figura da perita com a do Juízo, exigindo posicionamentos e mesmo a resolução de determinados conflitos ou a garantia de determinados direitos - o que não cabia a mim em absoluto.

Da parte dos proprietários, havia a questão dos prejuízos materiais que tiveram durante os eventos ocorridos na região no final de 2003, quando os Guarani ocuparam as propriedades localizadas dentro do perímetro da TI Yvy Katu. E, para além dos prejuízos materiais, havia o desgaste emocional pelo qual passaram naquela ocasião e que vivenciam ainda, pois aguardam o desfecho da disputa judicial. A trajetória de vida foi por alguns deles narrada nas entrevistas realizadas por ocasião dos trabalhos in loco, e em muitos casos se trata de famílias que vivem há décadas na região, e que investiram toda uma vida de trabalho nos imóveis rurais de sua propriedade. A iminência de terem suas terras desapropriadas pelo andamento do processo administrativo gera muita animosidade na região do litígio judicial.

Para os Guarani não é diferente. É graças a esforços coletivos muito grandes 
e de importantes articulações internas e externas, que eles continuam presentes em seus territórios de ocupação tradicional, lutando por seus direitos e pela manutenção de sua cultura. E o desgaste sofrido por eles no período mais recente de sua história também é grande, tendo em vista que os processos (tanto o administrativo, quanto o judicial) já estão em andamento há anos, sem que se chegue a um desfecho. Apesar das áreas provisoriamente fixadas pela Justiça Federal em 2004 terem possibilitado que várias famílias ali se instalassem, construindo suas casas e roças (e diminuindo as pressões internas em Porto Lindo), as relações entre índios e não-índios se deterioraram na região, e os conflitos agravaram-se ainda mais.

Há que se destacar que o que emerge das entrevistas é um panorama de violência contra os Guarani que ocorre há muito tempo, mas que nas últimas décadas se exacerba ainda mais. Alguns dos Guarani entrevistados por mim mencionaram ter recebido, na atualidade, ameaças de proprietários, ou mesmo terem sofrido algum tipo de violência física, para que não circulem dentro das propriedades. Isso passou a ocorrer principalmente depois de 2003 (justamente, a imposição de fortes restrições à circulação dos Guarani seria uma estratégia dos proprietários de terras para tentar quebrar o vínculo da comunidade indígena com seu antigo território). E muitas famílias, em Porto Lindo ou no perímetro que provisoriamente ocupam na área demarcada, vivem em situação de extrema vulnerabilidade socioeconômica.

A presença da perita e da(o)s assistentes técnica(o)s na região em 2011 criou nessas pessoas a expectativa de que a situação poderia chegar finalmente a um desfecho. Mas quando retornei em 2013 para realizar a segunda perícia, a situação foi de muita tensão, pois ficou claro para as pessoas envolvidas, principalmente os Guarani, que o fim do litígio ainda não estava próximo. E como é preciso usar nos laudos periciais os dados coletados em campo na presença da(o) $\mathrm{s}$ assistentes técnica(o)s das diferentes partes envolvidas no processo, muitas das pessoas entrevistadas por ocasião da segunda perícia foram demandadas a falar de temas já comentados anteriormente (em 2011) e muita(o)s se revoltaram com isso, afirmando que estávamos duvidando dela(e)s e até mesmo ameaçando não cooperar. Isso num contexto em que, para poder esclarecer se houve ou não ocupação tradicional na área do litígio, se fazia necessário reconstruir as relações que se estabeleciam e se estabelecem ainda entre as famílias indígenas e o local que está sendo reivindicado por elas atualmente. Ou seja: era fundamental trabalhar com as narrativas do próprio grupo. E nesse sentido, uma outra dificuldade se colocou: muitas das pessoas que vivenciaram os fatos que procurávamos escla- 
recer estão já em idade avançada e, em alguns casos, com a saúde debilitada, de forma que as entrevistas eram ocasiões muito cansativas para elas. Outras se recusaram a ser entrevistadas novamente. Soma-se a isso toda a questão das dificuldades ligadas à tradução para o caso de quem não falava português ou que, mesmo falando um pouco, preferia expressar-se em guarani.

Estes são apenas alguns dos pontos possíveis de serem destacados dentro da problemática inerente ao trabalho de peritagem. Apesar de todas as dificuldades e negociações necessárias, as falas dos Guarani entrevistados nas duas ocasiões (2011 e 2013) foram cruciais para a elaboração dos laudos periciais e para a reconstituição de sua trajetória na região e dos acontecimentos que teriam resultado na sua saída dos locais atualmente reivindicados. Para além das dificuldades encontradas por mim para recompor essa trajetória, o que fica evidente é a clareza que os Guarani têm de seu território e a força dos vínculos que continuam mantendo com ele. A presença dos Guarani-Ñandéva na região está fortemente marcada na própria memória individual e coletiva das famílias indígenas: em suas narrativas sobre seus antepassados, nas trajetórias biográficas das pessoas, nas lembranças ligadas aos rituais, aos grandes caciques, e ao próprio espaço físico e suas transformações ao longo do tempo.

\section{REFERÊNCIAS}

ALMEIDA, Ledson Kurtz. Laudo pericial antropológico relativo à reivindicação da Terra Indígena Sombrerito. Naviraí: 1 ${ }^{\text {a }}$ Vara da Justiça Federal, 2012.

ARRUDA, Gilmar. Heródoto. In: Ciclo da erva-mate em Mato Grosso do Sul 1883-1947. Campo Grande: Inst. Euvaldo Lodi, 1986.

ALBERNAZ, Adriana Cristina Repelevicz de. Antropologia, histórias e temporalidades entre os Avá-Guarani de Oco'y (PR). Tese de doutorado em Antropologia Social. Florianópolis: UFSC, 2009.

BARBOZA, Genésio Pimentel. Relatório de viagem. Ministério da Agricultura, Indústria e Comércio. Serviço de Proteção aos Índios. Inspetoria do Estado de Mato Grosso. Microfilme 025. Museu do Índio, 1927.

BARROS, Valéria Esteves. N. Da casa de rezas à Congregação Cristã no Brasil: o pentecostalismo guarani na Terra Indígena Laranjinha/PR. Dissertação de mestrado em Antropologia Social. UFSC: Florianópolis, 2003.

. Mito e história nas narrativas dos Guarani da bacia do Paranapa- 
nema. Tese de doutorado em Antropologia Social. UFSC: Florianópolis, 2011.

BRAND, Antonio. O impacto da perda da terra sobre a tradição Kaiowa/Guarani: os difíceis caminhos da palavra. Tese de doutorado em História. Porto Alegre: PUC/RS, 1997.

CARDOSO DE OLIVEIRA, Roberto. O Trabalho do Antropólogo. Brasília/ São Paulo: Paralelo Quinze/Editora da Unesp, 1998.

COLMAN, Rosa S. Território e sustentabilidade: os Guarani e Kaiowá de Yvy Katu. Dissertação de mestrado. Campo Grande: UCDB, 2007.

COUTO, Cristiane Beatriz Dahmer. História da implantação da educação escolar indígena na comunidade nãndeva-guarani na reserva de Porto Lindo no município de Japorã, MS. Dissertação de mestrado em Educação. Londrina: UEL, 2007.

FERREIRA, Eva Maria Luiz. A participação dos índios Kaiowá e Guarani como trabalhadores nos ervais da Companhia Matte Laranjeira (1902-1952). Dissertação de mestrado em História. Dourados: UFGD, 2007.

GEERTZ, Clifford. A interpretação das culturas. Rio de Janeiro: LTC Editora, 1989

UFRJ, 2005.

Obras e vidas: o antropólogo como autor. Rio de Janeiro: Editora

LANDA, Beatriz dos Santos. Os Ñandéva/Guarani e o uso do espaço na Terra Indígena Porto Lindo/Jakarey, município de Japorã/MS. Tese de doutorado em Arqueologia. Porto Alegre: PUC, 2005.

MELIÀ, Bartomeu. El pueblo guarani: unidad y fragmentos. In: Tellus, ano 4, n.6, p.151-162. Campo Grande, abr. 2004.

MELLO, Flávia C. Aetcha nhanderukuery karai retarã. Entre deuses e animais: xamanismo, parentesco e transformação entre os Chiripá e Mbyá Guarani. Tese de doutorado em Antropologia Social. Florianópolis: UFSC, 2006.

MONTEIRO, Maria Elizabeth B. Relatório referente ao levantamento histórico sobre os índios Kaiwá situados no estado de Mato Grosso do Sul. Rio de Janeiro: Museu do Índio [documentação xerocada], 1981.

MOTA, Lúcio Tadeu. O aço, a cruz e a terra: índios e brancos no Paraná provincial (1853-1889). Tese de doutorado em História. UNESP, Assis: 1998.

MURA, Fabio ; THOMAZ DE ALMEIDA, Rubem. Relatório Antropológico de Revisão de Limites da T.I. Porto Lindo (Jakarey) que resultou na identificação da Terra Indígena Guarani Nandéva Yvy Katu. 2002. 
OLIVEIRA, Jorge Eremites e PEREIRA, Levi Marques. Nande Ru Marangatu: laudo pericial sobre uma terra kaiowa na fronteira do Brasil com o Paraguai, em Mato Grosso do Sul. Dourados: UFGD, 2009.

. Terra Indígena Buriti: perícia antropológica, arqueológica e histórica sobre uma terra terena na Serra de Maracaju, Mato Grosso do Sul. Dourados: Ed. UFGD, 2012.

PEREIRA, Levi Marques. Imagens kaiowa do sistema social e seu entorno. Tese de doutorado em Antropologia. São Paulo: USP, 2004.

SALSA CORRÊA, Lúcia. A fronteira indígena no sul de Mato Grosso - século XIX. Fontes comentadas. In: Tellus. Campo Grande, 2(2): 155-159, 2002.

SANTOS, Silvio Coelhos dos. Índios e brancos no sul do Brasil: a dramática experiência dos Xocleng. Porto Alegre, Movimento; Brasília, Minc/Pró-Memória/ INL: 1987.

SCHADEN, Egon. Aspectos fundamentais da cultura guarani. São Paulo: Difusão Europeia do Livro, 1962.

THOMAZ DE ALMEIDA, Rubem F. Do desenvolvimento comunitário à mobilização política: o Projeto Kaiowa Ñandeva como experiência antropológica. Rio de Janeiro: Contra Capa Livraria e LACED, 2001.

TOMMASINO, Kimiye. A história dos Kaingang da bacia do Tibagi: uma sociedade Jê meridional em movimento. Tese de doutorado em Antropologia Social. Universidade de São Paulo, São Paulo: 1995. 


\title{
CONSIDERACIONES SOBRE EL PAPEL DEL ANTROPÓLOGO COMO EXPERTO JUDICIAL EN RECONOCIMIENTO OFICIAL DE TIERRAS INDIGGENAS DE UN CASO GUARANI NANDÉVA
}

\begin{abstract}
Resumen: El objetivo de este articulo es reflexionar sobre los procesos de reconocimiento oficial de tierras indígenas en Mato Grosso do Sul de un área reclamada por una comunidad guaraní ñandéva y que fue identificada como la tekoha Yvy Katu a través de un proceso administrativo. llevado a cabo por FUNAI y que resultó en la publicación de la Ordenanza No. 1289 del 30 de junio de 2005, que declara que la tierra indígena Yvy Katu está en posesión permanente del grupo guaraní en cuestión. Las demandas presentadas por los terratenientes dentro del perímetro delimitado suspendieron el progreso del procedimiento administrativo. En el contexto de esta disputa, realicé dos encuestas antropológicas en la región en cuestión: una en 2011 y otra en 2013. Uno de los puntos centrales que se aclaró aquí fue cómo y por qué los guaraníes habrían dejado de vivir en la tierra actualmente reivindicada. Y esto, a su vez, se conecta con otro eje de discusión propuesto por este grupo de trabajo: las violaciones de los derechos de los guaraníes en Mato Grosso do Sul. Por lo tanto, a partir de los datos recopilados durante mi desempeño como experto, tengo la intención de hacer algunas consideraciones. sobre aspectos principalmente metodológicos y éticos que plantean diferentes desafíos para los antropólogos involucrados en las diferentes etapas de los procesos de reconocimiento oficial de tierras indígenas y en la conducción de la experiencia antropológica en la esfera judicial.
\end{abstract}

Palabras clave: Antropólogo. Proceso de reconocimiento. Tierras guaraníes.

\section{CONSIDERATIONS ON THE TASK OF THE ANTHROPOLOGIST AS A JUDICIAL EXPERT IN OFFICIAL RECOGNITION OF INDIGENOUS LANDS FROM A GUARANI ÑANDÉVA CASE}

Abstract: The aim of this paper is to reflect on the processes of official recognition of indigenous land in Mato Grosso do Sul from an area claimed by a Guarani ñandéva community and which was identified as the tekoha Yvy Katu through an administrative process. conducted by FUNAI and which resulted in the publication of Ordinance No. 1289 of June 30, 2005, which declares that the indigenous land Yvy Katu is in permanent possession of the Guarani group in question. Law- 
suits filed by landowners within the bounded perimeter suspended the progress of the administrative proceeding. In the context of this dispute, I conducted two anthropological surveys in the region in question - one in 2011 and one in 2013. One of the central points to be clarified here was how and why the Guarani would have ceased to live on the currently vindicated land. And this, in turn, connects with another axis of discussion proposed by this working group: the violations of the rights of the Guarani in Mato Grosso do Sul. Thus, starting from the data collected during my performance as an expert, I intend to make some considerations. on mainly methodological and ethical aspects that pose different challenges for anthropologists involved in the different stages of the processes of official recognition of indigenous lands and in conducting anthropological expertise in the judicial sphere.

Keywods: Anthropologist. Recognition Process. Guarani lands. 